\title{
Bayesian inferences suggest that Amazon Yunga Natives diverged from Andeans less than 5000 ybp: implications for South American prehistory
}

\author{
Marilia O Scliar ${ }^{1}$, Mateus H Gouveia', Andrea Benazzo², Silvia Ghirotto², Nelson JR Fagundes ${ }^{3}$, Thiago P Leal', \\ Wagner CS Magalhães ${ }^{1}$, Latife Pereira ${ }^{1}$, Maira R Rodrigues ${ }^{1}$, Giordano B Soares-Souza', Lilia Cabrera ${ }^{4}$, \\ Douglas E Berg ${ }^{5,6}$, Robert H Gilman ${ }^{4,7,8}$, Giorgio Bertorelle ${ }^{2}$ and Eduardo Tarazona-Santos ${ }^{1 *}$
}

\begin{abstract}
Background: Archaeology reports millenary cultural contacts between Peruvian Coast-Andes and the Amazon Yunga, a rainforest transitional region between Andes and Lower Amazonia. To clarify the relationships between cultural and biological evolution of these populations, in particular between Amazon Yungas and Andeans, we used DNA-sequence data, a model-based Bayesian approach and several statistical validations to infer a set of demographic parameters.

Results: We found that the genetic diversity of the Shimaa (an Amazon Yunga population) is a subset of that of Quechuas from Central-Andes. Using the Isolation-with-Migration population genetics model, we inferred that the Shimaa ancestors were a small subgroup that split less than 5300 years ago (after the development of complex societies) from an ancestral Andean population. After the split, the most plausible scenario compatible with our results is that the ancestors of Shimaas moved toward the Peruvian Amazon Yunga and incorporated the culture and language of some of their neighbors, but not a substantial amount of their genes. We validated our results using Approximate Bayesian Computations, posterior predictive tests and the analysis of pseudo-observed datasets.

Conclusions: We presented a case study in which model-based Bayesian approaches, combined with necessary statistical validations, shed light into the prehistoric demographic relationship between Andeans and a population from the Amazon Yunga. Our results offer a testable model for the peopling of this large transitional environmental region between the Andes and the Lower Amazonia. However, studies on larger samples and involving more populations of these regions are necessary to confirm if the predominant Andean biological origin of the Shimaas is the rule, and not the exception.
\end{abstract}

Keywords: Population genetics inferences, Human evolution, Native American

\section{Background}

Knowing how Native Americans dispersed along the American continent is still a major challenge faced by researchers studying the biological and cultural evolution of the region [1-3]. Also, how natives adapted to diverse environmental challenges such as hypoxia and cold weather in the Andes [4] and the tropical forest [5] remain poorly understood.

\footnotetext{
* Correspondence: edutars@icb.ufmg.br

${ }^{1}$ Departamento de Biologia Geral, Instituto de Ciências Biológicas,

Universidade Federal de Minas Gerais, Belo Horizonte, Brazil

Full list of author information is available at the end of the article
}

When Europeans arrived in South America in the 16th century, the Pan-Andean Inca Empire dominated the Andean region and had a population density and levels of socioeconomic development unmatched elsewhere in South America. But the Inca Empire is just the tip of the iceberg of a long-term cultural and biological evolutionary process that involved the entire Andean region and its adjacent Pacific Coast (hereafter western South America). This process began 14-11 thousand years BP, with the peopling of this region in the Late Pleistocene [2], involving continuous cultural exchanges and gene flow along time, and leading to a relative genetic, cultural, and linguistic homogeneity between the populations of western 
South America when compared with eastern South America (a term that hereafter refers to the eastern region of the Andes, including the low Amazon Basin), where populations remained relatively more isolated [6] than those in western South America. For example, only two languages still predominate across the entire Andean region (Quechua and Aymara), whereas in eastern South America natives speak a wider spectrum of languages belonging to four different linguistic families [7]. Also, despite some controversy about definitions and chronology, archeologists consensually recognize three temporal Horizons in the Andes and the Pacific Coast (Early, Middle, and Late). Each of the Horizons corresponds to periods of material cultural dispersion involving a wide geographic area and, in the case of Middle and Late Horizons, to the expansion of the Wari-Tiwanaku and Inca States, respectively [8].

The current knowledge about western South American prehistory derives mainly from a plethora of archeological studies [9], most of which have focused on the Pacific Coast and Andean people. However, the relationships between Andeans and their culturally, linguistically, and environmentally different eastern neighbors living in the Amazon Yunga remain relatively neglected by archeologists, despite early investigations by Lathrap [10] and some subsequent studies that have been done on the subject [11]. Notwithstanding this knowledge gap, the Amazon Yunga, a region hosting at least six ethnic groups, is particularly interesting because it is a transitional environment between the Andes highlands and the lowland tropical forest of the Amazonia. Moreover, archeological research in the lowland Amazonia during the last decades has changed the traditional view of the Amazonian environment as incompatible with complex pre-Columbian societies [12]. The emerging view, that has gained growing support, recognizes that the Amazonian basin has hosted the earliest ceramics of South America, that endogenous agricultural societies with complex organization have developed there, and that population sizes were larger than previously thought $[13,14]$. In contrast, information derived from anthropological genetics is scantier, especially for Amazonian and Amazon Yunga populations [15-18]. Contributing to our poor understating of how these populations evolved is the fact that Native Americans are under-represented in modern genetic studies [19] due to cultural issues and logistic difficulties in reaching them in the tropical forest.

Cultural and commercial interactions occurring along the last millennia among the people living in the Peruvian Coast, the Andes and the Amazon Yunga regions are archaeologically documented. For example, cultivated plants such as sweet potato and manioc, ceramic iconography and styles (Tutishcanyo, Kotosh, and Valdivia) and traditional coca chewing [14] have been shared among Coast, Andean and Amazon Yunga populations. However, we ignore how the demographic evolutionary history of these populations accompanied their cultural and socioeconomic interactions. Specifically, and this is the goal of this study, we aimed to investigate the demographic relationships between the Shimaa population and their western Andean neighbors. Our study is the first to analyze a sample of the Amazon Yunga population at a multilocus level. Here we show that the genetic diversity of the Shimaa, a Matsiguenga Arawak-speaking population settled in and with an Amazon Yunga lifestyle, is a subset of the Andean Quechua diversity. We used a Bayesian inference framework and several statistical validation tools to infer that the Shimaa likely originated from an ancestral Andean population less than 5300 years ago, around or after the time when complex societies in the Andean region emerged.

\section{Results and discussion}

We used genetic data and a population genetic model to infer the evolutionary relationships between a Quechua population from the Peruvian Central Andean Highlands and an Arawak Matsiguenga population (Shimaa) from the Southern Peruvian Amazon Yunga (Additional file 1: Figure S1). These populations, separated by $300 \mathrm{~km}$, speak languages from different families (Pan-Andean Quechua and Arawak Matsiguenga, respectively) and have different cultures related to their high altitude Andean and rainforest Amazon Yunga lifestyles, respectively. We sequenced 10 independent genomic regions for a total of $\sim 20 \mathrm{~kb}$ per individual [20] in 11 Quechua and 10 Shimaa individuals, for whom we estimated [21] negligible non-native genetic contribution $(<5 \%$ in Quechuas in Scliar et al. [22], and $~ 1 \%$ in Shimaas, Additional file 1: Figure S2), based on genotyping of 106 Ancestry Informative Markers [23]. We used a model-based Bayesian approach to infer the posterior distributions of a set of demographic parameters [24]. The tested model considers and distinguishes the effects of genetic drift after the split of two populations and the subsequent gene flow between them in an explicit probabilistic framework (Figure 1). We inferred the parameters of the model using the likelihood-based method implemented in the software IM. This method uses the entire information provided by the data and applies a Markov Chain Monte Carlo (MCMC) computational approach [24]. Even though this model reduces the complex history of two populations, that actually evolve together with surrounding groups, to an only-two-populations system, simulation studies have shown that inferences are robust, despite moderate violations of the model assumptions, which were simulated to mimic comparable situations often encountered in real-world scenarios [25].

We found that Amazon Yunga Shimaas have a low genetic diversity that interestingly, is a subset of the higher diversity observed in the Andean Quechuas. In fact, more SNPs are found in the Quechuas than in the Shimaas and 


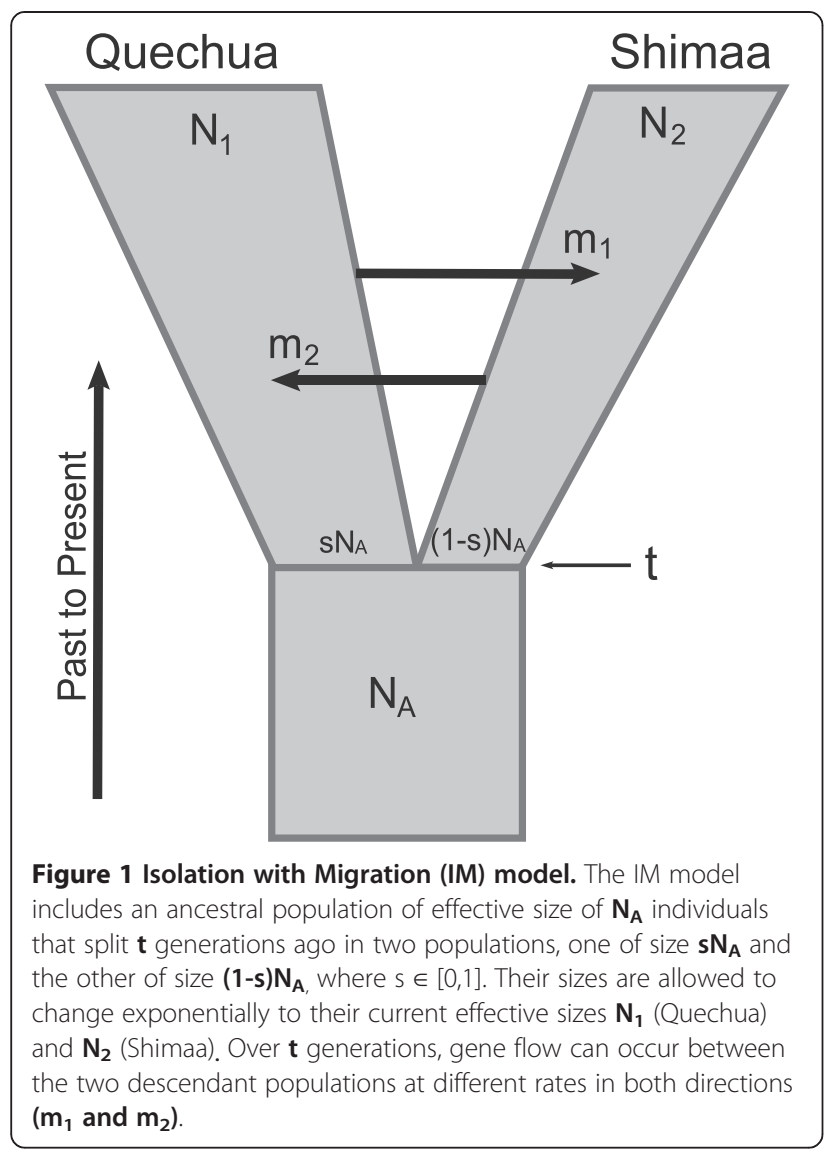

all the SNPs found in the Shimaa are shared with the Quechuas (Additional file 1: Table S3). The distribution of the mass probability of the divergence time posterior density (Figure 2 and Table 1) suggests that the Quechua and the Shimaa populations diverged recently: If the point estimate appears implausible, the upper limit of the $90 \%$ density interval excludes a divergence older than 5300 years ago. At the time of the split, individuals carrying $\mathrm{s} \approx 96 \%$ (Figure 3, Table 1) of the effective population size of the ancestral population founded the Quechua population, while only a small fraction $(s \approx 4 \%)$ founded the Shimaa. This statement does not necessarily mean that the individuals that founded the Shimaa were around 1/25 of the ancestral population. Instead, in population genetics, the definition of effective population size implies that respect to the ancestral Quechua population, the ancestral Shimaa population behaved as an ideal Wright-Fisher model population that lost diversity due to the action of the genetic drift at a pace around twenty-five times faster. Therefore, the lower effective population of the Shimaa may have resulted from a combination of a certainly much smaller number of individuals together with other factors known to reduce the effective population size, such as a biased sex ratio or a high variance in the number of progeny [26].
We validated our MCMC results by assessing the statistical convergence of multiple MCMC runs and by performing posterior predictive tests [27], and both procedures confirmed our inferences (Additional file 1: Section 2.1). To further validate our results, and because the IM model implemented in the MCMC framework [24] does not consider genetic intra-locus recombination, we also inferred the model parameters (Figure 1) by Approximate Bayesian Computations ( $\mathrm{ABC}$ ) [28], although our analyzed dataset shows almost no intra-locus recombination (see Methods). While the MCMC-approach uses the complete dataset at a cost of less flexibility of the model (for example, not allowing recombination), $\mathrm{ABC}$ allows more flexibility (in this case, the inclusion of recombination), but it only uses summary statistics to compare simulated and real data. This suboptimal use by ABC of the available information in analyzed datasets comes at a cost of larger credible intervals [29]. To analyze the consequences of considering recombination in the $\mathrm{ABC}$, we did one analysis with recombination $\left(\mathrm{ABC}_{-} \mathrm{rec}\right)$ and one without recombination $(\mathrm{ABC})$. The $\mathrm{ABC}$ estimates of the ancestral population size and the relative ratio of the two population sizes at the time of the split are similar to the IM estimates (Table 1). We inferred an earlier population divergence, though the point estimates with $A B C$ is still within the $90 \%$ interval obtained with the MCMC approach. We found, however, that $\mathrm{ABC}$ tended to overestimate the divergence time with our data (see pseudo-observed datasets validation in Additional file 1: Section 2.2). Similar results are obtained regardless the inclusion of recombination in the $\mathrm{ABC}$. Overall, our $\mathrm{ABC}$ estimates confirm our MCMC results (Figures 2 and 3, Table 1, and Additional file 1: Section 2.2).

Our results indicate that the Shimaa diverged from the Quechua Andean population after the late Pleistocene peopling of South America, and very likely, less than 5300 years ago. The 5000-3000 years period BP was characterized by the development of complex societies in the Andean Region and the Pacific Coast, being a period of major cultural development, when large permanent communities settled, monumental architecture appeared, pottery came into use, and agriculture became the predominant source of food supply (see Figure 2 and its references in Additional file 2). Representative settlements of that time were Kotosh in the Amazon Yunga (Huanuco Region), La Galgada in the Central Andes, and Caral and El Paraiso in the Central Pacific Coast (Figure 2). The initial dispersal of the Arawak, which is the language currently spoken by the Shimaa, also seems to have occurred during this time [29], and some authors (see Figure 2), suggest this linguistic family has originated in the Peruvian Amazon Yunga [30-32]. The most plausible scenario compatible with our results is that a small subpopulation (the ancestors of the Shimaa) split from a 

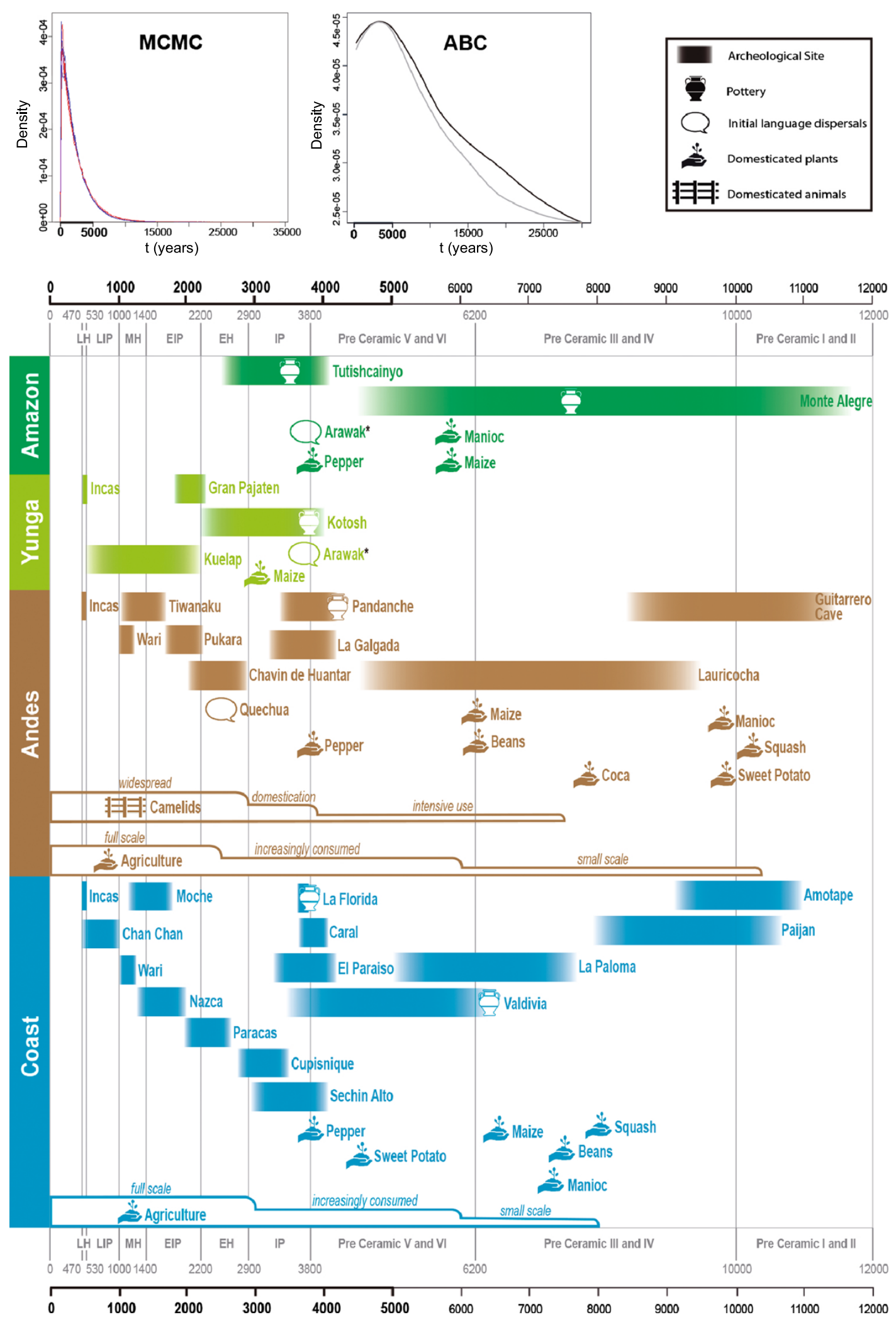

Figure $\mathbf{2}$ (See legend on next page.) 
(See figure on previous page.)

Figure 2 Posterior probabilities for the time of divergence between Quechua and Shimaa in its historical context. Posterior probability densities for the time of divergence $t$ (years) between Quechua and Shimaa populations, obtained by MCMC and ABC, in its historical context. The period encompassing the $90 \%$ HPD (Highest Posterior Density) interval of the posterior probability of $\mathbf{t}$, estimated by MCMC is highlighted. MCMC plot: Red: three independent runs with migration rate parameters $M_{i}=10$; Blue: three independent runs with migration rate parameters $M_{i}=0$. ABC plot: Gray: model without intra-locus recombination; Black: model with intra-locus recombination. Below are key historical events of Peruvian prehistory in four Peruvian longitudinal regions: Coast, Andes, Amazon Yunga and Amazonia. Pottery and cultivars symbols represent the earliest archaeological record for the region. This chronology is a simplified picture of the Peruvian archaeological history in which we used different dating records for its construction. To account for time uncertainties, we depicted the events in the chronology plot without clearly defined chronological borders. References for the historical events presented are specified in Additional file 2. LH: Late Horizon, LIP: Late Intermediate Period, MH: Middle Horizon, EIP: Early Intermediate Period, EH: Early Horizon, IP: Initial Period. *Controversial geographic region of Arawak origin. Each step in Agriculture and Camelids representations shows an increase in their relative importance.

larger Andean population, moved toward the Peruvian Amazon Yunga and then adapted to the different lifestyle of the Amazon Yunga, incorporating the culture of some of their neighbors and their language (Arawak), but not a substantial amount of their genes.

\section{Conclusions}

The question about the evolutionary relationship between Andean and the Lower Amazonian populations (i.e. if they derived from different migration routes into South America) is still open in American anthropology. We contributed to clarify -for the first time using multilocus data; the prehistoric demographic relationship between Andeans and a population from the Amazon Yunga. Moreover, our results offer a testable model for the peopling of this large transitional environmental region between the Andes and the Lower Amazonia. Andean populations are highly homogeneous [6,15-18] which supports our assumption that the Quechua sample used in this study is a fair representative of Andean populations. Nevertheless, further studies on the populations of the Amazon Yunga and the Lower Amazonia are necessary to show if the predominant Andean biological origin of the Shimaas and its pattern of adaptation to the new environment is the rule, and not the exception.

\section{Methods}

\section{Dataset}

We studied Native Americans from two Peruvian populations: (i) 11 Andean Quechua individuals reported in
Scliar et al. [22] and (ii) 10 Matsiguenga individuals from the Shimaa population, randomly selected from a total sample of 180 individuals available at our laboratory. The Matsiguenga are settled in this area of the Amazon Yunga since the 16th century [33]. This study was conducted under approval of the Institutional Reviews Boards from the Universidad Peruana Cayetano Heredia, Asociación Benéfica PRISMA, Universidade Federal de Minas Gerais and Johns Hopkins University. Detailed information about the re-sequencing of the 10 autosomal non-coding unlinked loci [20] used in this study is available in Scliar et al. [22] and in Additional file 1: Section 1.1. Sequence analysis were performed following the pipeline specified in Machado et al. [34]. We used 106 Ancestry Informative Markers [23] to perform admixture analyses of these individuals, using the software Structure [21], as detailed in Additional file 1: Section 1.2. The Shimaa dataset is available in GenBank [GenBank: KF690381-KF690580]. Additional file 3 presents the individual genotypes of the dataset used for the analysis that contains the 52 segregating sites identified in this study.

\section{MCMC inferences}

We used the IM program, that uses MCMC simulations of genealogies to estimate seven parameters of the Isolation-with-Migration model depicted in Figure 1 $[24,35]$ : three population mutation rate parameters for the ancestral and the two descendant populations $\left(\theta_{\mathrm{A}}, \theta_{1}\right.$, and $\theta_{2}$, respectively, where $\theta=4 \mathrm{~N}_{\mathrm{e}} \mu$ ); the splitting time parameter $(T=t \mu)$; the ratio of migration rate per mutation

Table 1 Estimates of demographic parameters

\begin{tabular}{lll}
\hline Demographic parameters & MCMC & ABC \\
\hline Time split $(t)$ & $193(15-5291)$ & $3300(250-26010)$ \\
N Ancestral $\left(N_{A}\right)$ & $5475(3766-7702)$ & $3829(741-25863)$ \\
N Shimaa $\left(N_{2}\right)$ & $681^{a}$ & $6449(5-34640)$ \\
$s^{b}$ & $0.96(0.17-0.99)$ & $0.89(0.21-0.99)$
\end{tabular}

Population size in number of individuals and time split in years. The estimates are the mode of the posterior distribution with the $90 \%$ HPD (Highest Posterior Density) interval between parentheses. MCMC estimates are the averages over six runs.

${ }^{a}$ We did not specified the $90 \%$ HPD for these estimates, because the right end of the posterior distribution did not approach zero in the vertical axis before the upper boundary of the prior distribution. This implies that the $90 \%$ HPD depends on the definition of the prior distribution.

${ }^{b}$ Fraction of the ancestral population that founded the Quechua population.

${ }^{\mathrm{C}}$ This parameter did not yield an informative density. 

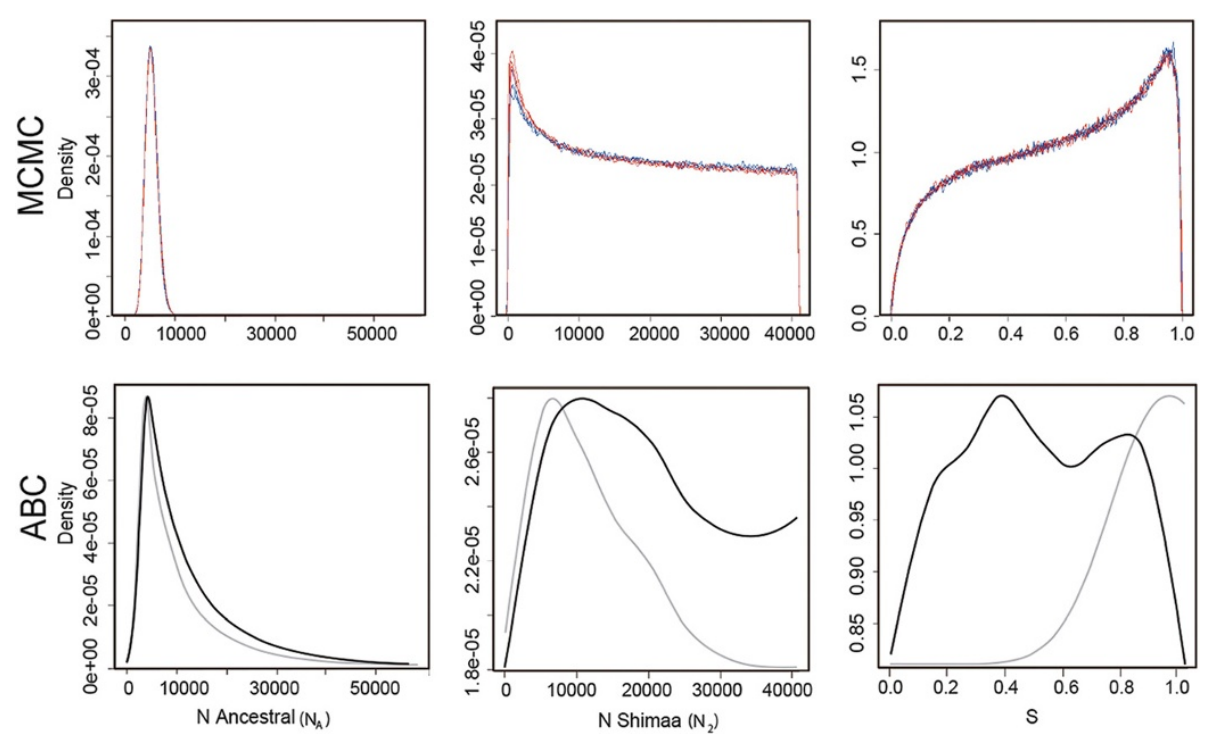

Figure 3 Posterior probabilities for the parameters $\mathbf{N}_{\mathbf{A}}, \mathbf{N}_{2}$, and $\mathbf{s}$. Posterior probability densities obtained by the MCMC method and by the $A B C$ for the parameters $N$ for ancestral effective size $\left(N_{A}\right)$, N Shimaa effective size $\left(N_{2}\right)$, and the $s$ parameter (the proportion of $N_{A}$ that founded the Quechua $\left(N_{1}\right)$ population. Range of prior probability distributions are in Additional file 1: Table $\mathbf{S} 2 . \mathbf{N}_{\mathbf{i}}$ are in number of individuals. $\mathbf{M C M C}$ plots: Red: three independent runs with migration rate parameters $M_{i}=10$; Blue: three independent runs with migration rate parameters $M_{i}=0$. ABC plots: Gray: model with no intra-locus recombination; Black: model with intra-locus recombination. Posterior probabilities for $N$ Quechua $\left(\mathbf{N}_{1}\right), \mathbf{m}_{\mathbf{1}}$ and $\mathbf{m}_{\mathbf{2}}$ did not yield informative densities and are presented in Additional file 1: Figure S3.

rate, in both directions $\left(M_{1}=m_{1} / \mu\right.$ and $\left.M_{2}=m_{2} / \mu\right)$, and the proportion of the ancestral population that founded population 1 (s) [24]. We assumed the infinite-site mutation model [36] for all loci. Except for s, the other model parameters are scaled by the neutral mutation rate $\mu$. Therefore, to obtain the demographic estimates $N_{e}$, $t$ and $\mathrm{m}$, a mutation rate needs to be assumed. Mutation rates for each locus were estimated using the BEAST software [37] assuming a divergence time of 6 million years between humans and chimpanzee. Under the multilocus model, the mutation rate is the geometric mean of the individual locus-specific mutation rates [24]. We used the geometric mean per year $\left(1.47 \times 10^{-6}\right)$ to obtain the estimated time since splitting, $t$, in years and migration rate, $\mathrm{m}$, per year. To obtain $\mathrm{N}_{\mathrm{e}}$, a measure of mutation rate on a scale of generations is needed. We assumed 25 years/generation, which yield a geometric mean value of $3.68 \times 10^{-5}$ mutations per generation.

Because the IM model originally assumes no recombination within loci, we used the program IMgc to find the largest subset of the data containing no signs of recombination. IMgc uses the four-gametes criteria to remove either sequences or variable sites containing evidence of recombination [38]. This procedure resulted in the removal of sequences QT80 and QT135 for locus 4, of sequence QA38 for locus 5, and of the second half segment of locus 3.

Three independent MCMC runs were performed, each with 30 Metropolis-coupled chains of 10 million steps using a geometric heating scheme and a burn-in period. Prior uniform distributions were defined as follows: $\theta_{\mathrm{i}} \in$ $(0,5), T \in(0,0.05), M_{i} \in(0,10)$, and $s \in(0,1)$. These scaled values correspond to the values specified in Additional file 1: Table S2. We also performed three independent runs without migration $\left(\mathrm{M}_{\mathrm{i}}=0\right.$ as prior), with 30 Metropolis-coupled chains of 8 million steps. We compared the results from the runs with and without migration, because Kitchen et al. [39] identified important changes in the estimates when using different migration rates as priors. Additional file 1: Section 1.3 details the criteria used to check convergence and MCMC results validation by posterior predictive test [27,40-42].

\section{Inferences by $A B C$}

To validate the results of the MCMC method by incorporating genetic intra-locus recombination (not allowed in the MCMC-IM model) in our analyses, we used ABC $[28,43]$ as a more general model framework, to infer the same seven demographic parameters of the MCMC model. We performed one analysis with recombination (ABC_rec) and one without recombination $(\mathrm{ABC})$. The $\mathrm{ABC}$ approach approximates the posterior distribution by performing a large number of simulations under a specific model and calculating the distance between Summary Statistics (SuSt) estimated from the simulated data and SuSt estimated from the observed data. We used the program fastsimcoal within the ABCToolBox for simulations [44-46]. Used 
prior distributions are given in Additional file 1: Table S2 and its rationale explained in the Additional file 1: Section 1.4 when necessary. SuSt used in the $A B C$ analyses are explained in detail in the Additional file 1: Section 1.4. Additional file 1: Table S3 presents the SuSt estimates for the observed data. For parameter estimation, we calculated the Euclidian distance between the simulated and observed SuSt and retained the 1\% of the total simulations corresponding to the shortest distances. Posterior probability for each parameter was estimated using a weighted local regression [28]. We assessed the quality of the parameters estimated by $\mathrm{ABC}$ by assessing the determination coefficient $R^{2}$ (the proportion of parameter variance explained by the summary statistics), by analyzing pseudoobserved datasets and by posterior predictive tests [27], as detailed in the Additional file 1: Section 1.5.

\section{Availability of supporting data section}

New sequence data generated for this study have been deposited in GenBank (http://www.ncbi.nlm.nih.gov/genbank) under accession numbers KF690381 to KF690580.

\section{Additional files}

Additional file 1: Contain supplementary material: the file includes supplementary methods description, supplementary results, Tables S1-S7, Figures S1-S4, and references exclusive of Additional file 1.

Additional file 2: References used to prepare Figure 2.

Additional file 3: Individual genotypes of the dataset used for the analysis, that contains the $\mathbf{5 2}$ segregating sites identified in this study.

\section{Competing interests}

The authors declare that they have no competing interests.

\begin{abstract}
Authors' contribution
Wrote the manuscript: MOS, ET-S. Conceived and designed the study: MOS, ET-S. Coordinated the project with Native American: ET-S, DEB, RHG. Organized and performed sample collection: LC, DEB, RHG. Supervised population genetics and statistical analyses: GB, ET-S. Performed laboratory work: MOS, LP. Performed statistical and population genetics analyses: MOS, MHG, AB, SG, LP, GBSS, NJRF. Provided bioinformatics or analytical tools: AB, SG, MOS, MHG, TPL, WSM, MRR. All authors read, contributed with discussion and approved the final manuscript.
\end{abstract}

\section{Acknowledgements}

We thank Fernando L Soares for preparation of figures, Silvia Fuselli, Guido Barbujani, Rosangela Loschi, Renato Assunção, Ricardo Santos, Celso Teixeira Mendes Junior and Juan C Riveros for discussions. Funding agencies: Fogarty International Center and National Cancer Institute-US (5R01TW007894), Brazilian National Research Council (CNPq), Brazilian CAPES Agency, Brazilian Ministry of Health (PNPD-Saúde Program), and the Minas Gerais State Research Agency (FAPEMIG) to E.T-S group. National Institutes of Health-US R21AI078237 and R21Al088337 to D.E.B.

\section{Author details}

${ }^{1}$ Departamento de Biologia Geral, Instituto de Ciências Biológicas, Universidade Federal de Minas Gerais, Belo Horizonte, Brazil. ${ }^{2}$ Dipartimento di Scienze della Vita e Biotecnologie, Università di Ferrara, Ferrara, Italy. ${ }^{3}$ Departamento de Genética, Instituto de Biociências, Universidade Federal do Rio Grande do Sul, Porto Alegre, Brazil. ${ }^{4}$ Asociación Benéfica PRISMA, Lima, Peru. ${ }^{5}$ Department of Molecular Microbiology, Washington University
School of Medicine, St. Louis, USA. ${ }^{6}$ Department of Medicine, University of California San Diego, San Diego, USA. ${ }^{7}$ Bloomberg School of Public Health, Johns Hopkins University, Baltimore, USA. ${ }^{8}$ Universidad Peruana Cayetano Heredia, Lima, Peru.

Received: 8 April 2014 Accepted: 24 July 2014

Published online: 30 September 2014

\section{References}

1. Salzano FM, Callegari-Jacques SM: South American Indians - A Case Study in Evolution. Oxford: Clarendon Press; 1988.

2. Dillehay TD: The Settlement of the Americas: A New Prehistory. New York: Basic Books; 2000.

3. Heggarty P, Beresford-Jones DG: Archaeology and Language in the Andes. Oxford: Oxford University Press; 2012.

4. Tarazona-Santos E, Lavine M, Pastor S, Fiori G, Pettener D: Hematological and pulmonary responses to high altitude in Quechuas: a multivariate approach. Am J Phys Anthropol 2000, 176:165-176.

5. Erickson CL: Amazonia: the historical ecology of a domesticated landscape. In The Handbook of South American Archaeology. Edited by Silverman H, Isbell WH. New York: Springer; 2008:157-183.

6. Tarazona-Santos E, Carvalho-Silva DR, Pettener D, Luiselli D, De Stefano GF, Labarga CM, Rickards O, Tyler-Smith C, Pena SDJ, Santos FR: Genetic differentiation in South Amerindians is related to environmental and cultural diversity: evidence from the Y chromosome. Am J Hum Genet 2001, 68:1485-1496.

7. Campbell L: American Indian Languages, The Historical Linguistics of Native American. Oxford: Oxford University Press; 1997.

8. Pozorski S, Pozorski T: Chronology. In The Origins and Development of the Andean State. Edited by Haas J, Pozorski S, Pozorski T. Cambridge: Cambridge University Press; 1987:5-8.

9. Silverman H: Andean Archaeology. Hoboken: Wiley Blackwell; 2004.

10. Lathrap DW: The Upper Amazon. New York: Praeger; 1970.

11. Raymond JS: A view from the tropical forest. In Peruvian Prehistory. Edited by Keatinge RW. Cambridge: Cambridge University Press; 1988:279-302.

12. Roosevelt AC, Lima da Costa M, Lopes Machado C, Michab M, Mercier N, Valladas H, Feathers J, Barnett W, Imazio da Silveira M, Henderson A, Silva J, Chernoff B, Reese DS, Holman JÁ, Toth N, Schick K: Paleoindian cave dwellers in the Amazon: the peopling of the Americas. Science 1996, 272:373-384.

13. Roosevelt AC: The maritime, highland, forest dynamic and the origins of complex culture. In The Cambridge History of the Native Peoples of the Americas, Volume 3. Edited by Salomon F, Schwartz SB. Cambridge: Cambridge University Press; 1999:264-349.

14. Silverman H, Isbell WH: The Handbook of South American Archaeology. New York: Springer; 2008.

15. Fuselli S, Tarazona-Santos E, Dupanloup I, Soto A, Luiselli D, Pettener D: Mitochondrial DNA diversity in South America and the genetic history of Andean highlanders. Mol Biol Evol 2003, 20:1682-1691.

16. Wang S, Lewis CM, Jakobsson M, Ramachandran S, Ray N, Bedoya G, Rojas W, Parra MV, Molina JA, Gallo C, Mazzotti G, Poletti G, Hill K, Hurtado AM, Labuda D, Klitz W, Barrantes R, Bortolini MC, Salzano FM, Petzl-Erler ML, Tsuneto LT, Llop E, Rothhammer F, Excoffier L, Feldman MW, Rosenberg $N A$, Ruiz-Linares A: Genetic variation and population structure in native Americans. PLoS Genet 2007, 3:e185.

17. Reich D, Patterson N, Campbell D, Tandon A, Mazieres S, Ray N, Parra MV, Rojas W, Duque C, Mesa N, García LF, Triana O, Blair S, Maestre A, Dib JC, Bravi CM, Bailliet G, Corach D, Hünemeier T, Bortolini MC, Salzano FM, Petzl-Erler ML, Acuña-Alonzo V, Aguilar-Salinas C, Canizales-Quinteros S, Tusié-Luna T, Riba L, Rodríguez-Cruz M, Lopez-Alarcón M, Coral-Vazquez R, et al: Reconstructing Native American population history. Nature 2012, 488:370-374.

18. Sandoval JR, Lacerda DR, Jota MS, Salazar-Granara A, Vieira PP, Acosta O, Cuellar C, Revollo S, Fujita R, Santos FR, Genographic Project Consortium: The genetic history of indigenous populations of the Peruvian and Bolivian Altiplano: the legacy of the Uros. PLoS One 2013, 8:e73006.

19. Bustamante CD, Burchard EG, De la Vega FM: Genomics for the world. Nature 2011, 475:163-165.

20. Frisse L, Hudson RR, Bartoszewicz A, Wall JD, Donfack J, Di Rienzo A: Gene conversion and different population histories may explain the contrast between polymorphism and linkage disequilibrium levels. Am J Hum Genet 2001, 69:831-843. 
21. Pritchard JK, Stephens M, Donnelly P: Inference of population structure using multilocus genotype data. Genetics 2000, 155:945-959.

22. Scliar MO, Soares-Souza GB, Chevitarese J, Lemos L, Magalhães WCS, Fagundes NJ, Bonatto SL, Yeager M, Chanock SJ, Tarazona-Santos E: The population genetics of Quechuas, the largest native South American group: autosomal sequences, SNPs, and microsatellites evidence high level of diversity. Am J Phys Anthropol 2012, 147:443-451.

23. Pereira L, Zamudio R, Soares-Souza G, Herrera P, Cabrera L, Hooper CC, Cok J, Combe JM, Vargas G, Prado WA, Schneider S, Kehdy F, Rodrigues MR, Chanock SJ, Berg DE, Gilman RH, Tarazona-Santos E: Socioeconomic and nutritional factors account for the association of gastric cancer with Amerindian ancestry in a Latin American admixed population. PLoS One 2012, 7:e41200.

24. Hey J: On the number of New World founders: a population genetic portrait of the peopling of the Americas. PLOS Biol 2005, 3:e193.

25. Strasburg JL, Rieseberg LH: How robust are "isolation with migration" analyses to violations of the im model? A simulation study. Mol Biol Evol 2010, 27:297-310.

26. Hedrick PW: Genetics of Populations. Falmouth: Jones \& Bartlett Publishers; 2009.

27. Gelman A, Carlin JB, Stern HS, Rubin DB: Bayesian Data Analysis. London: Chapman \& Hall/CRC; 2004.

28. Beaumont MA, Zhang W, Balding DJ: Approximate Bayesian computation in population genetics. Genetics 2002, 162:2025-2035.

29. Zucchi A: The Arawakan matrix: ethos, language, and history in Native South America. In Comparative Arawakan Histories: Rethinking Language and Culture Area in Amazonia. Edited by Hill JD, Santos-Granero F. Urbana: University of Illinois Press; 2002:199-222.

30. Noble GK: Proto-Arawakan and its Descendants. Bloomington: Indiana University; 1965.

31. Urban G: A história brasileira segundo as línguas nativas. In História dos Indios no Brasil. Edited by Cunha MC. São Paulo: FAPESP; 1992:82-102.

32. Walker RS, Ribeiro LA: Bayesian phylogeography of the Arawak expansion in lowland South America. Proc Biol Sci 2011, 278:2562-2567.

33. Salomon F, Schwartz SB: The Cambridge History of the Native Peoples of the Americas, Volume 3, Part 2. Cambridge: Cambridge Univ. Press; 1999.

34. Machado M, Magalhães WC, Sene A, Araújo B, Faria-Campos AC, Chanock SJ, Scott L, Oliveira G, Tarazona-Santos E, Rodrigues MR: Phred-Phrap package to analyses tools: a pipeline to facilitate population genetics re-sequencing studies. Investig Genet 2011, 2:3.

35. Hey J, Nielsen R: Multilocus methods for estimating population sizes, migration rates and divergence time, with applications to the divergence of Drosophila pseudoobscura and D. persimilis. Genetics 2004, 167:747-760

36. Kimura M: The number of heterozygous nucleotide sites maintained in a finite population due to steady flux of mutations. Genetics 1969, 61:893-903.

37. Drummond AJ, Rambaut A: BEAST: Bayesian evolutionary analysis by sampling trees. BMC Evol Biol 2007, 7:214.

38. Woerner AE, Cox MP, Hammer MF: Recombination-filtered genomic datasets by information maximization. Bioinformatics 2007, 23:1851-1853.

39. Kitchen A, Miyamoto MM, Mulligan CJ: A three-stage colonization model for the peopling of the Americas. PLoS One 2008, 3:e1596.

40. Kuhner MK: Coalescent genealogy samplers: windows into population history. Trends Ecol Evol 2009, 24:86-93.

41. Ghirotto S, Mona S, Benazzo A, Paparazzo F, Caramelli D, Barbujani G: Inferring genealogical processes from patterns of Bronze-Age and modern DNA variation in Sardinia. Mol Biol Evol 2010, 27:875-886.

42. Voight BF, Adams AM, Frisse LA, Qian Y, Hudson RR, Di Rienzo A: Interrogating multiple aspects of variation in a full resequencing data set to infer human population size changes. Proc Natl Acad Sci U S A 2005, 102:18508-18513.

43. Bertorelle $\mathrm{G}$, Benazzo A, Mona S: $A B C$ as a flexible framework to estimate demography over space and time: some cons, many pros. Mol Ecol 2010, 19:2609-2625.
44. Excoffier L, Lischer HEL: Arlequin suite ver 3.5: a new series of programs to perform population genetics analyses under Linux and Windows. Mol Ecol Resour 2010, 10:564-567.

45. Excoffier L, Foll M: Fastsimcoal: a continuous-time coalescent simulator of genomic diversity under arbitrarily complex evolutionary scenarios. Bioinformatics 2011, 27:1332-1334.

46. Wegmann D, Leuenberger C, Neuenschwander S, Excoffier L: ABCtoolbox: a versatile toolkit for approximate Bayesian computations. BMC Bioinformatics 2010, 11:116.

doi:10.1186/s12862-014-0174-3

Cite this article as: Scliar et al:: Bayesian inferences suggest that Amazon Yunga Natives diverged from Andeans less than $5000 \mathrm{ybp}$ : implications for South American prehistory. BMC Evolutionary Biology 2014 14:174.

\section{Submit your next manuscript to BioMed Central and take full advantage of:}

- Convenient online submission

- Thorough peer review

- No space constraints or color figure charges

- Immediate publication on acceptance

- Inclusion in PubMed, CAS, Scopus and Google Scholar

- Research which is freely available for redistribution 